\title{
Socio-behavioral Factors Associated to Caries Prevalence and DMFT Index in Adolescents and Young Adults in a Developing Country \\ JO García-Cortés ${ }^{1}$, JP Loyola-Rodriguez ${ }^{1}$, A Loyola-Leyva ${ }^{1}$, J de Jesús Navarrete-Hernández ${ }^{2}$, S Márquez-Rodríguez ${ }^{2}$, MÁ Fernández-Barrera², CE Medina-Solís ${ }^{2,3}$
}

\begin{abstract}
Objective: To determine the factors associated with the prevalence of dental caries and decayed, missing, and filled teeth index (DMFT) in adolescents and young adults using logistic and negative binomial regression.

Methods: A cross-sectional epidemiological study was conducted on a sample of 638 subjects 16-25 years of age in San Luis Potosi, Mexico. Binary logistic regression was used to generate a model of the prevalence of caries and negative binomial regression was used to model the caries experience (DMFT index). Clinical examination was carried out by dentists trained in the criteria of caries (WHO). The independent variables were collected using questionnaires. Analyses were performed in Stata.

Results: In multivariate models, it was observed that lower maternal education $(\mathrm{OR}=1.95)$, dental health services utilization (DHSU) $(\mathrm{OR}=2.25)$ and reporting "good" oral health $(\mathrm{OR}=0.34)$ were associated $(\mathrm{p}$ $<0.05)$ with the prevalence of caries (DMFT>0). For those who experience caries (DMFT), female gender, lower maternal education and DHSU increased the expected mean of DMFT by $26 \%, 22.4 \%$ and $36.7 \%$, respectively. In addition, self-reported "regular" and "good" oral health declined 30.0\% and $47.0 \%$, the expected average DMFT.
\end{abstract}

Conclusions: The variables associated with the prevalence of caries (DMFT $>0$ ) and the DMFT were the same in the models used, except for sex. The mother's schooling proved the existence of certain socioeconomic inequalities in oral health.

Keywords: Adolescents, dental caries, health inequalities, Mexico, oral health

From: ${ }^{1}$ Advanced Education in General Dentistry, Master Degree Program Autonomous University of San Luis Potosí. San Luis Potosí, México. ${ }^{2}$ Academic Area of Dentistry of Health Sciences Institute at Autonomous University of Hidalgo State. Pachuca, Mexico. ${ }^{3}$ Advanced Studies and Research Center in Dentistry "Dr. Keisaburo Miyata", Faculty of Dentistry, Autonomous University State of Mexico. Toluca, México.

Correspondence: Dr CE Medina-Solís, Avenida del Álamo \# 204, Fraccionamiento Paseo de los Solares Santiago Tlapacoya, Pachuca de Soto, Hidalgo, ZP. 42110, México. E-mail: cemedinas@yahoo.com 
Factores socio-conductuales asociados a la prevalencia de caries y al índice CPOD en adolescentes y adultos jóvenes en un país en desarrollo

\section{Resumen}

Objetivo: Determinar los factores asociados a la prevalencia de caries dental y al índice de dientes cariados perdidos y obturados (CPOD) en adolescentes y adultos jóvenes empleando análisis de regresión logística y binomial negativa.

Material y Métodos: Se llevo a cabo un estudio epidemiológico transversal en una muestra de 638 sujetos de 16 a 25 años de edad en San Luis Potosí, México. Se utilizó regresión logística binaria para generar un modelo de la prevalencia de caries y otro de regresión binomial negativa para modelar la experiencia de caries (índice CPOD). Los exámenes clínicos lo realizaron dentistas capacitados en el criterio de caries (OMS). Las variables independientes se recogieron utilizando cuestionarios. Los análisis se ejecutaron en Stata.

Resultados: En los modelos multivariados, se observó que la menor escolaridad de la madre $(\mathrm{RM}=1.95)$, la utilización de servicios de salud bucal (USSB) $(\mathrm{RM}=2.25)$ y el reporte de "buena" salud bucal $(\mathrm{RM}=0.34)$ se asociaron $(\mathrm{p}<0.05)$ a la prevalencia de caries $(\mathrm{CPOD}>0)$. Para la experiencia de caries (CPOD): el sexo femenino, la menor escolaridad de la madre y la USSB incrementaron la media esperada del CPOD en $26.0 \%, 22.4 \%$ y $36.7 \%$, respectivamente. Por otro lado, el autoreporte de salud bucal "regular" y "bueno" disminuyó en 30.0\% y 47.0\%, la media esperada del CPOD.

Conclusiones: Las variables asociadas a la prevalencia de caries (CPOD $>0)$ y al índice CPOD fueron las mismas en los modelos utilizados, excepto para sexo. La escolaridad de la madre demuestra la existencia de ciertas desigualdades socioeconómicas en salud bucal.

Palabras clave: salud bucal; caries dental; adolescentes; desigualdades en salud; México. 


\section{INTRODUCTION}

Dental caries is one of the most prevalent chronic diseases in the world and one of the primary causes of pain and suffering. It also has physical, psychological and economic implications. Due to its high prevalence and incidence, it is considered to be the main problem in oral public health. Even though it is reversible in its early stages, when settled, caries progresses slowly, causing destruction of the hard tissues of the tooth and becomes a major cause of tooth mortality if not controlled by appropriate treatment. Similarly, being a cumulative disease, once it occurs, its manifestation persists throughout life even after receiving dental treatment $(1,2)$. Epidemiological studies conducted in recent years on caries in preschoolers $(3,4)$, school children $(5,6)$ and adolescents $(7,8)$ in developing countries like Mexico have shown that it is a problem of oral public health, observing high unmet health needs for what is essentially a preventable disease. These studies have mainly focused on preschool and school age children. Consequently, the state of oral health in adolescents over 15 years old and young adults under 25 years old represents a large gap in knowledge at the national and international level (9).

According to the report "The Global Burden of oral conditions in 1990-2010" derived from "The Global Burden of Disease (GBD) 2010 Study", untreated caries in permanent dentition is the most common problem and the highest burden of disease (10). In world literature it is mentioned that the presence of dental biofilm is considered an etiologic factor for caries ( 1 , 11). In addition, there are several associated factors that can modulate its appearance, supporting the evidence that caries is a multifactorial disease. Variables consistently related to this condition are parents' schooling $(7,12)$, predominantly the mothers' education, household income (12), race (13), health insurance (13), as well oral hygiene practices such as regular brushing and the use of other devices for oral hygiene $(1,12,14)$. Other variables include certain lifestyles habits 
such as smoking $(13,14)$, consumption of sweet snacks $(14)$, experience with health services and clinical variables such as previous dental treatment $(7,14,15)$, experience of dental illness (16), enamel defects $(16,17)$, oral health programs like fluoridation $(13,18)$ or the application of dental sealants (13). Additionally, socio-demographic variables such as age and sex could contribute to the development of dental caries $(7,13,14,16)$.

The analytical approach that is done in most studies is dichotomized into those with caries experience $(\mathrm{DMFT}>0)$ and those without caries $(\mathrm{DMFT}=0)$, i.e., they analyze the prevalence of caries. This perspective is not wrong; however, information about people who have more severe caries is lost. Furthermore, linear regression analysis is occasionally used to analyze the DMFT (decayed, missing, and filled teeth) index. However, an assumption for this model is that the dependent variable must be on a continuous scale because DMFT index is a count variable, and thus this approach is erroneous.

The aim of this study was to determine factors associated with the prevalence of caries using logistic regression analysis and DMFT index using negative binomial regression model on a sample of Mexican adolescents and young adults.

\section{MATERIAL AND METHODS}

\section{Design, population and study sample}

This report is part of a project where various oral health indicators were measured. A study was performed with a cross-sectional design in which adolescents and young adults from 16 to 25 years were included. The subjects were randomly selected from the students applying for undergraduate programs from San Luis Potosi University (UASLP), which is the public state 
university and concentrates the majority of people who want university education. The sample size was calculated based on a previous study (8). Since the previous study was used to estimate several oral health indicators, the calculation of sample size took into consideration the following criteria: $75 \%$ ratio estimate, $95 \%$ confidence level, an accuracy of $3.5 \%$ and a non-response rate of $10 \%$. With these criteria, a sample size of 653 was determined. The inclusion criteria included: a) both genders, b) age between 16-25 years old and c) a complete application to enter UASLP. Exclusion criteria were as follows: a) subject who completed the process, but did not attend their clinical oral examination, b) presence of orthodontic appliances and c) incomplete questionnaires with less than $90 \%$ of items answered. Accounting for the inclusion and exclusion criteria, the final sample size was 638 subjects, $97.7 \%$ of the calculated sample size.

\section{Data collection and variables shaping}

DMFT index (decayed, missing, and filled teeth) was used for detecting dental caries. This index is recommended by the WHO and is accepted internationally for epidemiological studies on oral health. All subjects were clinically examined by one of two examiners (trained and standardized, Kappa $>0.85$ ) to identify dental caries using a flat dental mirror, probe and artificial light. The dependent variables were the DMFT index and the prevalence of caries, and a model was generated for each variable. Sociodemographic, socioeconomic and behavioral variables were collected with a previously validated questionnaire. The independent variables included in this study were: sex $(0=$ male, $1=$ female $)$, age $(16-25$ years $)$, number of individuals that share the same household spending ( 1 to 11$)$, work other than studying $(0=$ No, $1=$ yes), mother and father schooling $(0=$ high school and more, $1=$ less than high school), having a car at home $(0=y e s$, $1=$ no), socioeconomic status (in tertiles), holding health insurance $(0=$ with insurance, $1=$ uninsured), oral pain in the 12 months prior the study $(0=$ no, $1=$ yes $)$, use of oral health 
services (USSB) in the 12 months prior to the study $(0=$ no, $1=$ yes $)$, frequency of tooth brushing $(0=$ less than twice/day, $1=$ at least twice/day $)$, tobacco consumption $(0=$ never, $1=$ former smokers, $2=$ current smoker), fruit consumption (in tertiles), consumption of sweet snacks (in tertiles), consumption of dairy products (in tertiles), self-report of oral health status (0 $=$ poor/very poor, $1=$ moderate, $2=\operatorname{good} /$ very good), and oral health knowledge (in tertiles).

Principal components analysis (PCA) was undertaken, specifically polychoric correlation (19) to reduce the dimensions of certain variables and to construct the socioeconomic position, consumption of fruits, sweet snacks, dairy products and oral health knowledge factors were streamlined into one principal component. Following this analysis, the components generated were divided into tertiles where the first tertile represented the group with the lowest condition and the third tertile represented the group with the highest condition.

\section{Statistical analysis}

An univariate analysis was performed to report measures of central tendency and dispersion for continuous variables, as well as frequencies and percentages for categorical variables. For the bivariate analysis, $\mathrm{X}^{2}$, Mann-Whitney and Kruskall-Wallis tests were performed according to the measuring scale of the tested variables. Logistic regression was implemented to model the prevalence of caries (DMFT $>0)$ and negative binomial regression for the DMFT index. The latter regression analysis is designed to model counting variables so that DMFT is a discrete variable (count) that can only have integer values. Since the DMFT is not a continuous variable, the lineal regression model is dismissed. In addition, there is over-dispersion (the variance is higher than the mean) with the analysis, the mean was 4.24 and the variance was 14.82 , dismissing the Poisson model. Under this model using latter regression analysis, the association 
of exposure variables with disease severity was evaluated instead of only the presence or the absence of the event.

Variables that showed a $p$ value $<0.25$ (20) in the bivariate analysis were included in the analytical models. The statistical package Stata $11 \circledR$ was used.

\section{Ethical considerations}

This study was carried out according to the General Health Law in research and scientific principles of Helsinki. All subjects signed informed consent. The protocol was approved by the Advanced Education in General Dentistry, Master Degree Program at San Luis Potosi, Mexico.

\section{RESULTS}

A total of 638 subjects with a mean age of $18.76 \pm 1.76$ were evaluated. The gender distribution was 324 men (50.8\%) and 314 women (49.2\%). The descriptive results are summarized in Table I. Some students, 31.8\%, performed part-time work outside of their studies. In the studied sample, the mean family size was 4 members. Additionally, $57.2 \%$ of the mothers and $43.6 \%$ of the fathers had an educational level lower than high school. Within the households, $80.4 \%$ had a car and $64.3 \%$ had some type of health insurance. In the 12 months prior to the study, $34.0 \%$ had experienced oral or dental pain and $63.8 \%$ used dental health services. A brushing frequency of at least twice a day was reported by $81.5 \%$ of the participants. Current use of tobacco was reported by $20.9 \%$ of subjects, while $5.6 \%$ were considered to be former users. Of all individuals surveyed, $36.1 \%$ self-reported as having good oral health and most $(50.8 \%)$ considered themselves to have moderate oral health. As mentioned in the methodology section, socioeconomic status, fruit consumption, sweet snacks, dairy products and oral health knowledge 
were divided into tertiles. DMFT index was $4.24 \pm 3.85$ and caries prevalence was $76.5 \%$. The results of the DMTF index distribution and the caries prevalence through the independent categorical variables included in the study are shown in Tables II and III.

The multivariate models are shown in Tables IV and V. For the caries prevalence (DMFT $>0$ ), it was observed that adolescents and young adults whose mother had a lower education level had a significantly increased $(\mathrm{OR}=1.95$; IC95\%=1.33-2.87) chance of presenting caries compared to adolescents and young adults whose mother had a higher education level. Subjects who attended oral health services during the year prior to the study had a higher possibility of presenting caries compared to those who did not attend to oral health services $(\mathrm{OR}=2.25$; IC95\%1.52-3.32). On the other hand, those subject who self-reported "good" oral health $(\mathrm{OR}=0.34)$ had a decreased possibility of developing dental caries (Table IV). The model for caries index (DMFT mean) is shown in Table V, indicating that female gender, decreased education of the mother and DHSU increased the expected mean for DMFT by $26.0 \%(\mathrm{p}=0.005)$, $22.4 \%(\mathrm{p}=0.015)$ and $36.7 \%(\mathrm{p}<0.001)$, respectively. On the other hand, "moderate" and "good" oral health self-reports decreased DMFT mean by $30.0 \%(\mathrm{p}=0.038)$ and $47.0 \%(\mathrm{p}=0.003)$, respectively.

\section{DISCUSSION}

The purpose of this study was to determine the socio-behavioral factors associated with caries indicators, the experience (mean DMFT) and the prevalence (DMFT $>0$ ) by using two different regression models. In this regard, certain variables associated with caries were observed in Mexican adolescents and young adults. It has been well documented in epidemiological studies 
that women have higher levels of caries compared to men $(13,14)$. Women and girls face disadvantages that are mainly due to inequity. Frequently in developing countries, discrimination exists against women and girls in health, education and the labor market. In health, more so than other sectors, variables such as sex (biological) and gender (behavioral and social) are recognized as useful parameters for research and action since biological differences between sexes determine specific diseases for men and women. For behavioral differences between genders, a key role is assigned to women in relation to family health (21). In regards to oral aspects of health, women have an earlier eruption compared to men, and thus oral exposure to the acidic environment is longer in females. It is necessary to express that in this study, the association between sex and caries, was observed only in caries experience (DMFT index) while showed no association with the caries of prevalence.

In recent years, there has been growing interest in social determinants related to health. Socioeconomic aspects have a wide influence on different aspects of general health. The results of this study on oral health are consistent with those made by other authors who also used mothers' education level as an indicator of socioeconomic position (SEP) $(7,12,16)$. It is known that a population with higher socioeconomic level presents better health, known as social gradient. Individual SEP is multidimensional and the main issues are education level and social class, based on occupation and income, leading to the major differences in health. The association between SEP and health could be a result of a difference in access to health information and access to oral health services.

Oral health services seem to have a negative effect on caries indicators such as DMFT and prevalence. This has been observed not only in Mexico, but also in several other countries $(1,7,15)$. The observed effect of these two variables could be due to the component "filled 
tooth" from DMFT, which had a higher percentage in this sample. This might be because DMFT is a risk indicator. A higher DMFT indicates a greater chance of presenting caries experience, but it points to past experiences and not treatment needs (or untreated caries). When used as a variable for the type of service used, it has been reported that the use of oral health services is a protective factor for dental caries (14).

For several years, there has been growing desire to measure the perception of health status in several scenarios. Currently, health self-reporting is one of the most widespread measures of perception evaluated in social epidemiology $(22,23)$. It is a common indicator of health status, and despite the lack of a direct clinical evidence, it correlates with more complex health measures (24). Self-reporting has been employed as a morbidity $(25,26)$ and mortality $(27$,$) predictor. In this regard, the present study showed that health perception behaves as a risk$ indicator for experience and dental caries prevalence.

This study failed to find an association between dental caries and several indicators. Therefore, the findings of this study contributed to the debate about the role of certain variables in the development of dental caries. For example, although tobacco use has had a proven effect on periodontal health (28), the correlation with dental caries has been controversial (29). Furthermore, dietary habits play an important role in dental caries etiology. The introduction of refined carbohydrates in the modern diet has been associated with an increase in dental experience and prevalence (30). Removal of plaque through tooth brushing also has been documented $(5,12)$. In this study, no relation to these variables and dental caries was found.

The study has limitations that should be taken into account when interpreting the results. The first limitation is related to design. Cross-sectional design measures cause and effect at the same time. This can result in cross ambiguity, therefore only detecting associations and not 
causal relationships. It is likely that the lack of association of several variables with dental caries is due to the selection of a homogeneous sample. It could also be due to the introduction of reporting bias in which subjects reported better conditions when in fact they were not.

Based on these results, we can conclude that, with the exception of sex, which is only associated with caries experience, the variables associated with caries prevalence (DMFT $>0)$ and DMFT index were the same in both regression models. Mothers' education level proves the existence of certain socioeconomic inequalities in oral health. It is necessary to explore the association of subjective variables such as oral health self-reporting with dental caries.

\section{AUTHORS' NOTE}

The authors declare no conflict of interests. 


\section{REFERENCES}

1. Herrera MS, Medina-Solís CE, Minaya-Sánchez M, Pontigo-Loyola AP, VillalobosRodelo JJ, Islas-Granillo H, et al. Dental plaque, preventive care, and tooth brushing associated with dental caries in primary teeth in schoolchildren ages 6-9 years of Leon, Nicaragua. Med Sci Monit 2013; 19: 1019-26.

2. Medina-Solís CE, Pontigo-Loyola AP, Pérez-Campos E, Hernández-Cruz P, De la RosaSantillana R, Navarete-Hernández JJ et al. Principal reasons for extraction of permanent tooth in a sample of Mexicans adults. Rev Invest Clin 2013; 65: 141-9.

3. Vázquez EM, Vázquez F, Barrientos MC, Córdova JA, Lin D, Beltrán FJ, et al. Association between asthma and dental caries in the primary dentition of Mexican children. World J Pediatr 2011; 7: 344-9.

4. Zuñiga-Manriquez AG, Medina-Solís CE, Lara-Carrillo E, Márquez-Corona ML, Robles Bermeo NL, Scougall-Vilchis RJ et al. [Experience, prevalence and severity of dental caries and its association with nutritional status in Mexican infants 17-47 months]. Rev Invest Clin. 2013; 65: 228-36.

5. Molina-Frechero N, Pierdant-Rodríguez AI, Oropeza-Oropeza A, Bologna-Molina R. Fluorosis and dental caries: an assessment of risk factors in Mexican children. Rev Invest Clin 2012; 64: 67-73.

6. Padilla-Suzuki BE, Llodra-Calvo JC, Belío-Reyes IA, García-Jau RA, Osuna-Ramírez I, Ramírez-Alvarez M, et al. Predicting risk of caries in schoolchildren from northwestern Mexico: longitudinal study. Rev Invest Clin 2013; 65: 24-9.

7. Pontigo-Loyola AP, Medina-Solis CE, Borges-Yáñez SA, Patiño-Marín N, Islas-Márquez AJ, Maupomé G. Prevalence and severity of dental caries in adolescents ages 12 and 15 
living in communities with various fluoride concentrations. J Public Health Dent 2007; 67: $8-13$.

8. García-Cortés JO, Medina-Solís CE, Loyola-Rodriguez JP, Mejía-Cruz JA, MedinaCerda E, Patiño-Marín $\mathrm{N}$ et al. Dental caries' experience, prevalence and severity in Mexican adolescents and young adults. Rev Salud Pública (Bogotá). 2009; 11: 82-91.

9. Skinner J, Johnson G, Phelan C, Blinkhorn A. Dental caries in 14- and 15-year-olds in New South Wales, Australia. BMC Public Health 2013; 13: 1060.

10. Marcenes W, Kassebaum NJ, Bernabé E, Flaxman A, Naghavi M, Lopez A, Murray CJ. Global burden of oral conditions in 1990-2010: a systematic analysis. J Dent Res 2013; 92: $592-7$.

11. Nyvad B, Crielaard W, Mira A, Takahashi N, Beighton D. Dental caries from a molecular microbiological perspective. Caries Res 2013; 47: 89-102.

12. Ayele FA, Taye BW, Ayele TA, Gelaye KA. Predictors of dental caries among children 7-14 years old in Northwest Ethiopia: a community based cross-sectional study. BMC Oral Health. 2013; 13: 7.

13. Ditmyer M, Dounis G, Mobley C, Schwarz E. A case-control study of determinants for high and low dental caries prevalence in Nevada youth. BMC Oral Health. 2010; 10-24.

14. Rwenyonyi CM, Muwazi LM, Buwembo W. Assessment of factors associated with dental caries in rural communities in Rakai District, Uganda. Clin Oral Investig 2011; 15: $75-80$.

15. Crocombe LA, Broadbent JM, Thomson WM, Brennan DS, Poulton R. Impact of dental visiting trajectory patterns on clinical oral health and oral health-related quality of life. $\mathrm{J}$ Public Health Dent 2012; 72: 36-44. 
16. Vallejos-Sánchez AA, Medina-Solís CE, Casanova-Rosado JF, Maupomé G, CasanovaRosado AJ, Minaya-Sánchez M. [Enamel defects, caries in primary dentition and fluoride sources: relationship with caries in permanent teeth]. Gac Sanit 2007; 21: 227-34.

17. Grošelj M, Jan J. Molar incisor hypomineralisation and dental caries among children in Slovenia. Eur J Paediatr Dent 2013; 14: 241-5.

18. Vitoria I, Maraver F, Almerich-Silla JM. [Fluoride content in tap water in Spain and prevention of dental caries]. Gac Sanit 2014; 28: 255-6.

19. Kolenikov S, Angeles G. The use of discrete data in Principal Component Analysis with applications to socio-economic indices. Working paper No. WP-04-85. Chapel Hill: CPC/MEASURE. 2004.

20. Sun GW, Shook TL, Kay GL. Inappropriate use of bivariable analysis to screen risk factors for use in multivariable analysis. J Clin Epidemiol 1996; 49: 907-16.

21. Buvinić M, Medici A, Fernández E, Torres AC. Gender Differentials in Health. In: Disease Control Priorities in Developing Countries. 2nd edition. Jamison DT, Breman JG, Measham AR, Alleyne G, Claeson M, Evans DB et al. editors. Washington (DC): World Bank; 2006.

22. Eriksson I, Unden AL, Elofsson S. Self-rated health. Comparisons between three different measures. Results from a population study. Int J Epidemiol 2001; 30: 326-33.

23. Laaksonen M, Rahkonen O, Martikainen P, Lahelma E. Socioeconomic position and selfrated health: the contribution of childhood socioeconomic circumstances, adult socioeconomic status, and material resources. Am J Public Health 2005; 95: 1403-9. 
24. Bayliss EA, Ellis JL, Shoup JA, Zeng C, McQuillan DB, Steiner JF. Association of patient-centered outcomes with patient-reported and ICD-9-based morbidity measures. Ann Fam Med 2012; 10: 126-33.

25. Riise HK, Riise T, Natvig GK, Daltveit AK. Poor self-rated health associated with an increased risk of subsequent development of lung cancer. Qual Life Res 2014; 23: 14553.

26. Galenkamp H, Huisman M, Braam AW, Schellevis FG, Deeg DJ. Disease prevalence based on older people's self-reports increased, but patient-general practitioner agreement remained stable, 1992-2009. J Clin Epidemiol 2014; 67: 773-80.

27. Tamayo-Fonseca N, Quesada JA, Nolasco A, Melchor I, Moncho J, Pereyra-Zamora P, López R, Calabuig J, Barber X. Self-rated health and mortality: a follow-up study of a Spanish population. Public Health. 2013; 127: 1097-104.

28. Tanaka K, Matsuse R, Miyake Y, Hanioka T, Arakawa M. Salivary cotinine concentrations and prevalence of periodontal disease in young japanese women: The Kyushu Okinawa Maternal and Child Health Study. J Periodontol 2013; 84: 1724-9.

29. Benedetti G, Campus G, Strohmenger L, Lingström P. Tobacco and dental caries: a systematic review. Acta Odontol Scand 2013; 71: 363-71.

30. Gupta P, Gupta N, Pawar AP, Birajdar SS, Natt AS, Singh HP. Role of sugar and sugar substitutes in dental caries: a review. ISRN Dent 2013; 2013: 519421. 
Table 1: Descriptive analysis of variables included in the study

\begin{tabular}{|c|c|c|}
\hline Variables & Mean \pm SD & Limits \\
\hline Age (years) & $18.76 \pm 1.76$ & $16-25$ \\
\hline \multirow[t]{2}{*}{ Household members } & $4.01 \pm 1.78$ & $1-11$ \\
\hline & Frequency & Percentage \\
\hline \multicolumn{3}{|l|}{ Sex } \\
\hline Men & 324 & 50.8 \\
\hline Women & 314 & 49.2 \\
\hline \multicolumn{3}{|l|}{ Work (besides studying) } \\
\hline No & 435 & 68.2 \\
\hline Yes & 203 & 31.8 \\
\hline \multicolumn{3}{|l|}{ Mother's schooling level } \\
\hline High school and more & 273 & 42.8 \\
\hline Less than high school & 365 & 57.2 \\
\hline \multicolumn{3}{|l|}{ Father's schooling level } \\
\hline High school and more & 360 & 56.4 \\
\hline Less than high school & 278 & 43.6 \\
\hline \multicolumn{3}{|l|}{ Socioeconomic position } \\
\hline 1st tertil & 217 & 34.0 \\
\hline 2nd tertil & 219 & 34.3 \\
\hline 3rd tertil & 202 & 31.7 \\
\hline \multicolumn{3}{|l|}{ Car in the household } \\
\hline Yes & 513 & 80.4 \\
\hline No & 125 & 19.6 \\
\hline \multicolumn{3}{|l|}{ Health insurance } \\
\hline With & 410 & 64.3 \\
\hline Without & 228 & 35.7 \\
\hline \multicolumn{3}{|c|}{ Pain in the previous 12 months } \\
\hline No & 421 & 66.0 \\
\hline $\mathrm{Si}$ & 217 & 34.0 \\
\hline \multicolumn{3}{|c|}{ DHSU in the previous 12 months } \\
\hline No & 231 & 36.2 \\
\hline Yes & 407 & 63.8 \\
\hline \multicolumn{3}{|l|}{ Frequency of tooth brushing } \\
\hline Less than twice a day & 118 & 18.5 \\
\hline Al least twice a day & 520 & 81.5 \\
\hline \multicolumn{3}{|l|}{ Tobacco use } \\
\hline Never & 469 & 73.5 \\
\hline Former smoker & 36 & 5.6 \\
\hline Smoker & 133 & 20.9 \\
\hline \multicolumn{3}{|l|}{ Fruit consumption } \\
\hline Low & 213 & 33.4 \\
\hline Medium & 213 & 33.4 \\
\hline High & 212 & 33.2 \\
\hline Sweet snacks consumptior & & \\
\hline
\end{tabular}


Garcia-Cortes et al

\begin{tabular}{lll}
\hline Low & 213 & 33.4 \\
Medium & 213 & 33.4 \\
$\quad$ High & 212 & 33.2 \\
Dairy consumption & & \\
$\quad$ Low & 213 & 33.4 \\
$\quad$ Medium & 214 & 33.5 \\
$\quad$ High & 211 & 33.1 \\
Oral health self-report & & \\
$\quad$ Bad & 84 & 13.2 \\
$\quad$ Moderate & 324 & 50.8 \\
$\quad$ Good & 230 & 36.1 \\
Oral health knowledge & & \\
$\quad$ Low & 248 & 38.9 \\
$\quad$ Medium & 184 & 28.8 \\
$\quad$ High & 206 & 32.3 \\
\hline
\end{tabular}


Table 2: Bivariate logistic regression analysis between caries prevalence and independent variables

\begin{tabular}{|c|c|c|c|}
\hline Variables & DMFT $>0$ & OR (IC95\%) & p value \\
\hline Age & 76.5 & $1.06(0.96-1.19)$ & 0.248 \\
\hline Household members & 76.5 & $1.07(0.96-1.19)$ & 0.193 \\
\hline \multicolumn{4}{|l|}{ Sex } \\
\hline Men & 75.3 & $1 *$ & \\
\hline Women & 77.7 & $1.14(0.79-1.65)$ & 0.475 \\
\hline \multicolumn{4}{|l|}{ Work (besides studying) } \\
\hline No & 76.8 & $1 *$ & \\
\hline Yes & 75.9 & $0.95(0.64-1.40)$ & 0.799 \\
\hline \multicolumn{4}{|l|}{ Mother's schooling level } \\
\hline High school and more & 70.3 & $1 *$ & \\
\hline Less than high school & 81.1 & $1.81(1.25-2.61)$ & 0.002 \\
\hline \multicolumn{4}{|l|}{ Father's schooling level } \\
\hline High school and more & 73.6 & $1 *$ & \\
\hline Less than high school & 80.2 & $1.45(1.00-2.12)$ & 0.052 \\
\hline \multicolumn{4}{|l|}{ Socioeconomic position } \\
\hline 1st tertil & 75.6 & $1 *$ & \\
\hline 2nd tertil & 78.5 & $1.18(0.76-1.85)$ & 0.462 \\
\hline 3rd tertil & 75.3 & $0.98(0.63-1.53)$ & 0.938 \\
\hline \multicolumn{4}{|l|}{ Car in the household } \\
\hline Yes & 76.6 & $1 *$ & \\
\hline No & 76.0 & $0.97(0.61-1.53)$ & 0.886 \\
\hline \multicolumn{4}{|l|}{ Health insurance } \\
\hline With & 76.1 & $1 *$ & \\
\hline Without & 77.2 & $1.06(0.72-1.56)$ & 0.755 \\
\hline \multicolumn{4}{|c|}{ Pain in the previous 12 months } \\
\hline No & 74.8 & $1 *$ & \\
\hline $\mathrm{Si}$ & 79.7 & $1.32(0.89-1.97)$ & 0.167 \\
\hline \multicolumn{4}{|c|}{ DHSU in the previous 12 months } \\
\hline No & 69.3 & $1 *$ & \\
\hline Yes & 80.6 & $1.84(1.27-2.67)$ & 0.001 \\
\hline \multicolumn{4}{|l|}{ Frequency of tooth brushing } \\
\hline Less than twice a day & 73.7 & $1 *$ & \\
\hline Al least twice a day & 77.1 & $1.20(0.76-1.90)$ & 0.434 \\
\hline \multicolumn{4}{|l|}{ Tobacco use } \\
\hline Never & 75.3 & $1 *$ & \\
\hline Former smoker & 86.1 & $2.04(0.77-5.36)$ & 0.149 \\
\hline Smoker & 78.2 & $1.18(0.74-1.87)$ & 0.486 \\
\hline \multicolumn{4}{|l|}{ Fruit consumption } \\
\hline Low & 73.2 & $1 *$ & \\
\hline Medium & 79.3 & $1.40(0.89-2.20)$ & 0.139 \\
\hline High & 76.9 & $1.21(0.78-1.89)$ & 0.385 \\
\hline Sweet snacks consumption & & & \\
\hline
\end{tabular}


Garcia-Cortes et al

\begin{tabular}{llll}
\hline Low & 75.6 & $1^{*}$ & \\
$\quad$ Medium & 78.4 & $1.17(0.75-1.84)$ & 0.490 \\
$\quad$ High & 75.5 & $0.99(0.64-1.55)$ & 0.978 \\
Dairy consumption & & & \\
$\quad$ Low & 74.6 & $1^{*}$ & \\
$\quad$ Medium & 75.7 & $1.06(0.68-1.64)$ & 0.801 \\
$\quad$ High & 79.1 & $1.29(0.82-2.03)$ & 0.272 \\
Oral health self-report & & & \\
$\quad$ Bad & 84.5 & $1^{*}$ & \\
$\quad$ Regular & 79.9 & $0.73(0.38-1.40)$ & 0.342 \\
$\quad$ Good & 68.7 & $0.40(0.21-0.77)$ & 0.006 \\
Oral health knowledge & & & \\
$\quad$ Low & 77.4 & $1^{*}$ & \\
$\quad$ Medium & 73.9 & $0.83(0.53-1.29)$ & 0.400 \\
$\quad$ High & 77.7 & $1.01(0.65-1.58)$ & 0.949 \\
\hline
\end{tabular}

*Reference category 
Table 3: Bivariate analysis of negative binomial regression between the DMFT and independent variables

\begin{tabular}{|c|c|c|c|c|}
\hline Variables & DMFT & coefficient & Change $\%$ & p value \\
\hline Age & $4.24 \pm 3.85$ & 0.0021 & No effect & 0.926 \\
\hline Household members & $4.24 \pm 3.85$ & 0.0255 & No effect & 0.271 \\
\hline \multicolumn{5}{|l|}{ Sex } \\
\hline Men & $3.70 \pm 3.33$ & $1 *$ & & \\
\hline Women & $4.79 \pm 4.26$ & 0.2571 & $29.3 \%$ & 0.002 \\
\hline \multicolumn{5}{|l|}{ Work (besides studying) } \\
\hline No & $4.28 \pm 3.92$ & $1 *$ & & \\
\hline Yes & $4.14 \pm 3.70$ & -0.0332 & No effect & 0.713 \\
\hline \multicolumn{5}{|l|}{ Mother's schooling level } \\
\hline High school and more & $3.78 \pm 3.87$ & $1 *$ & & \\
\hline Less than high school & $4.58 \pm 3.80$ & 0.1936 & $21.3 \%$ & 0.022 \\
\hline \multicolumn{5}{|l|}{ Father's schooling level } \\
\hline High school and more & $4.15 \pm 4.01$ & $1 *$ & & \\
\hline Less than high school & $4.36 \pm 3.63$ & 0.0491 & No effect & 0.562 \\
\hline \multicolumn{5}{|l|}{ Socioeconomic position } \\
\hline 1st tertil & $4.13 \pm 3.67$ & $1 *$ & & \\
\hline 2nd tertil & $4.29 \pm 3.90$ & 0.0366 & No effect & 0.719 \\
\hline 3rd tertil & $4.30 \pm 4.00$ & 0.0388 & No effect & 0.709 \\
\hline \multicolumn{5}{|l|}{ Car in the household } \\
\hline Yes & $4.15 \pm 3.85$ & $1 *$ & & \\
\hline No & $4.59 \pm 3.82$ & 0.1007 & No effect & 0.338 \\
\hline \multicolumn{5}{|l|}{ Health insurance } \\
\hline With & $4.16 \pm 3.69$ & $1 *$ & & \\
\hline Without & $4.38 \pm 4.12$ & 0.0522 & No effect & 0.551 \\
\hline \multicolumn{5}{|c|}{ Pain in the previous 12 months } \\
\hline No & $3.99 \pm 3.82$ & $1 *$ & & \\
\hline $\mathrm{Si}$ & $4.71 \pm 3.86$ & 0.1661 & No effect & 0.059 \\
\hline \multicolumn{5}{|c|}{ DHSU in the previous 12 months } \\
\hline No & $3.48 \pm 3.56$ & $1 *$ & & \\
\hline Yes & $4.66 \pm 3.94$ & 0.2918 & $33.9 \%$ & 0.001 \\
\hline \multicolumn{5}{|l|}{ Frequency of tooth brushing } \\
\hline Less than twice a day & $3.85 \pm 3.61$ & $1 *$ & & \\
\hline Al least twice a day & $4.33 \pm 3.90$ & 0.1174 & No effect & 0.281 \\
\hline \multicolumn{5}{|l|}{ Tobacco use } \\
\hline Never & $4.17 \pm 3.89$ & $1 *$ & & \\
\hline Former smoker & $4.55 \pm 3.92$ & 0.0893 & No effect & 0.624 \\
\hline Smoker & $4.41 \pm 3.68$ & 0.0559 & No effect & 0.590 \\
\hline \multicolumn{5}{|l|}{ Fruit consumption } \\
\hline Low & $3.98 \pm 3.92$ & $1 *$ & & \\
\hline Medium & $4.33 \pm 3.79$ & 0.0859 & No effect & 0.404 \\
\hline High & $4.40 \pm 3.84$ & 0.1025 & No effect & 0.320 \\
\hline Sweet snacks consumptior & & & & \\
\hline
\end{tabular}




\begin{tabular}{lcccc}
\hline Low & $4.06 \pm 3.73$ & $1^{*}$ & & \\
Medium & $4.64 \pm 4.24$ & 0.1328 & No effect & 0.194 \\
$\quad$ High & $4.00 \pm 3.53$ & -0.0151 & No effect & 0.884 \\
Dairy consumption & & & & \\
$\quad$ Low & $4.20 \pm 3.87$ & $1^{*}$ & & \\
$\quad$ Medium & $4.21 \pm 4.10$ & 0.0042 & No effect & 0.967 \\
$\quad$ High & $4.30 \pm 3.57$ & 0.0250 & No effect & 0.809 \\
Oral health self-report & & & & \\
$\quad$ Bad & $5.28 \pm 3.94$ & $1^{*}$ & & \\
$\quad$ Moderate & $4.25 \pm 3.71$ & -.2174 & No effect & 0.087 \\
$\quad$ Good & $3.83 \pm 3.94$ & -.3209 & $-38.9 \%$ & 0.016 \\
Oral health knowledge & & & & \\
$\quad$ Low & $4.12 \pm 3.59$ & $1^{*}$ & & \\
$\quad$ Medium & $4.46 \pm 4.43$ & 0.0805 & No effect & 0.435 \\
$\quad$ High & $4.18 \pm 3.60$ & 0.0163 & No effect & 0.871 \\
\hline
\end{tabular}

*Reference category

Table 4: Multivariate logistic regression model for the prevalence of caries (DMFT $>0)$ in college students

\begin{tabular}{lcc}
\hline Variables & OR (IC95\%) & p value \\
\hline $\begin{array}{l}\text { Mother's schooling level } \\
\quad \text { High school and more }\end{array}$ & $1^{*}$ \\
$\quad \begin{array}{c} \\
\text { Less than high school }\end{array}$ & $1.95(1.33-2.87)$ & 0.001 \\
DHSU in the previous 12 months & $1^{*}$ & \\
$\quad$ No & $2.25(1.52-3.32)$ & 0.000 \\
$\quad$ Yes & $1^{*}$ & \\
Oral health self-report & $0.64(0.33-1.26)$ & 0.203 \\
$\quad$ Bad & $0.34(0.17-0.67)$ & 0.002 \\
$\quad$ Moderate & & \\
$\quad$ Good & & \\
\hline
\end{tabular}

* Reference category. 
Table 5: Multivariate negative binomial regression model for DMFT in college students

\begin{tabular}{lllc}
\hline Variables & Coefficiente & Change \% & p value \\
\hline $\begin{array}{l}\text { Sex } \\
\quad \text { Men }\end{array}$ & $1^{*}$ & & \\
$\quad$ Women & 0.2267 & $26.0 \%$ & 0.005 \\
$\begin{array}{l}\text { Mother's education level } \\
\quad \text { High school and more }\end{array}$ & $1^{*}$ & & \\
$\quad$ Less than high school & 0.2024 & $22.4 \%$ & 0.015 \\
$\begin{array}{l}\text { DHSU in the previous 12 months } \\
\text { No }\end{array}$ & $1^{*}$ & & \\
$\quad$ Yes & 0.3092 & $36.7 \%$ & $<0.001$ \\
$\begin{array}{l}\text { Oral health self-report } \\
\text { Bad }\end{array}$ & $1 *$ & & \\
$\quad \begin{array}{l}\text { Moderate } \\
\text { Good }\end{array}$ & -0.2617 & $-30.0 \%$ & 0.038 \\
\hline Referce catgory & -0.3895 & $-47.0 \%$ & 0.003 \\
\hline
\end{tabular}

* Reference category. 